\title{
Investigation of Mechanical and Metallurgical Properties of Friction Stir Corner Welded Dissimilar Thickness AA5086-AA6061 Aluminium Alloys
}

\author{
Manigandan Krishnan ${ }^{a}$ 이, Senthil Kumar Subramaniam ${ }^{a}$ \\ ${ }^{a}$ School of Mechanical Engineering, Vellore Institute of Technology, Vellore, 632014, Tamilnadu, India
}

Received: November 28, 2017; Revised: March 10, 2018; Accepted: April 20, 2018

\begin{abstract}
In this investigation, an attempt has been made to fabricate dissimilar thickness corner joint using non-heat treatable (AA5086) and heat treatable (AA6061) dissimilar aluminium alloys by friction stir welding process with plate thicknesses of $6 \mathrm{~mm}$ and $4 \mathrm{~mm}$. Three parameters and three levels were considered to conduct the experiments such as welding and rotational speeds of 100,150 and $190 \mathrm{~mm} / \mathrm{min}$ and 900, 1000 and $1100 \mathrm{rpm}$ and plunge depth of $0.1,0.2$ and $0.3 \mathrm{~mm}$. The mechanical properties were evaluated using hardness and tensile tests. Taguchi grey relational analysis was carried out to determine the optimum process parameters. The higher value of tensile strength was obtained $192 \mathrm{MPa}$ at rotational and welding speeds of $1000 \mathrm{rpm}$ and $150 \mathrm{~mm} / \mathrm{min}$ which was $76.80 \%$ of parent material and maximum hardness was $157 \mathrm{HV}$ at thermomechanically affected zone for the rotational speed of $1100 \mathrm{rpm}$ and hardness at stir zone was maximum because of refined grain formation. The microstructures of various regions were observed and analyzed by optical and scanning electron microscopes. The tensile samples fractured at the heat affected zone. The spindle motor current consumption, work material temperature distribution, and force generation during friction stir welding were estimated and analyzed.
\end{abstract}

Keywords: Friction stir welding, Corner joint, Dissimilar thickness, Microstructure, Tensile strength, Hardness.

\section{Introduction}

Aluminium materials can be generally welded using fusion welding processes like gas tungsten arc welding and gas metal arc welding processes. Numerous welding defects occur in traditional fusion welding of aluminum alloys such as voids, hot cracking, distortion, precipitate dissolution, and lack of penetration in the joints. Friction stir welding is a solid-state welding process invented by Thomas W. of The Welding Institute (TWI), the United Kingdom in $1991^{1}$. The maximum temperature in the material being welded is usually less than $80 \%$ of its melting temperature. A non-consumable rotating tool is plunged into the abutting edges of the plates to be welded with sufficient axial force and advanced along the line of the joint. Frictional heat generated by the tool rotation softens the materials around the tool pin. The transverse movement of the tool pushes plastically deformed material from front to back of the tool and forges to complete the joining process. Friction stir welding used to weld non-ferrous metals such as aluminium alloys, copper, titanium, magnesium, and attempts have been made to weld dissimilar metals and steel. AA5086 is a non-heat treatable aluminium alloy exhibits higher strength to weight ratio, good ductility, easily weldable and good corrosion resistance widely used to produce marine, auto aircraft cryogenics, transportation equipment, and missile components. FSW is successfully applied for different joint designs such as butt joint, T- Joint, lap joint and corner joint. In the corner joints, materials to be welded clamped right angle to one another during FSW welding.

The corner joint was fabricated by FSW utilizing stationary shoulder rotating tool with AA6082-T6 filler material. The joints produced in the AA5083-O alloy failed at the base material regardless of the filler material utilized. The heat treatable alloy AA6061 in both tests failed at the heat affected zones. The highest tensile strength was obtained for AA5083-O joint was $310 \mathrm{MPa}^{1}$. The defect-free joints were produced by threaded cylindrical pin profile tools. The finer and uniformly distributed precipitates, circular onion rings and smaller grain were the reason for the better performance of the joints ${ }^{2}$. The uneven distribution of microhardness profile was most extreme in the weld zone and that twice higher than that of the base materials. The rotation speed of $600 \mathrm{rpm}$ and the welding speed of $40 \mathrm{~mm} / \mathrm{min}$ produced the better weld joint ${ }^{3}$. Increase in welding speed from $50 \mathrm{~mm} / \mathrm{min}$ to $200 \mathrm{~mm} / \mathrm{min}$ the average grain size was decreased from $6 \mu \mathrm{m}$ to $2 \mu \mathrm{m}$ and from $9 \mu \mathrm{m}$ to $3 \mu \mathrm{m}$ for the similar joints of the AA7075 alloy. The joints revealed the tensile strength of 245 and $267 \mathrm{MPa}$ with joint efficiencies between 77 and 
$87 \%$ with respect to the strength of AA5083 base metal ${ }^{4}$. The welded joint comprises the different zones, such as weld zone, thermomechanically affected zone, and heat affected zone. The welding speed impacts the formation of the plastically deformed joints. The mixed flow region was not exhibited in the weld by lower and higher welding speeds. The better tensile properties were produced by the joint created at a welding speed of $63 \mathrm{~mm} / \mathrm{min}^{5}$. The microhardness at weld zone was higher with $\mathrm{SiC}$ particles than that of without $\mathrm{SiC}$ particles as a result of the reduction in the grain size and aluminum matrix comprises strengthening SiC particles ${ }^{6}$.

A limited literature is available on the study of friction stir welding of corner joints with dissimilar plate thicknesses. Hence an attempt has been made to investigate mechanical and metallurgical properties of dissimilar thickness friction stir corner welded AA5086 - AA6061 dissimilar aluminium alloys at the different combination of process parameters. Further analysis of microstructure was carried out with SEM micrographs and fractographs of the welds.

\section{Experimental Procedure}

Aluminum alloys AA5086-O and AA6061-T6 were used in this work. The chemical composition and mechanical properties of the alloys are shown in Table $1 \&$ Table 2. Specimens with dimensions of $100 \mathrm{~mm} \times 50 \mathrm{~mm} \times 6 \mathrm{~mm}$ made from AA5086 alloy clamped vertically and $100 \mathrm{~mm} \times$ $50 \mathrm{~mm} \times 4 \mathrm{~mm}$ were made from AA6061 alloy clamped horizontally normal to each other in order to produce corner joints. A tool with $18 \mathrm{~mm}$ shoulder diameter and $3.7 \mathrm{~mm}$ length of cylindrical threaded pin profile was used. The tool was machined from D2 tool steel and heat treated to 58 HRC. The dissimilar thickness corner joint was done on the vertical milling machine (Figure 1). The tool tilt angle, tool offset and axial force are the other process parameters of friction stir welding. The rotational speed, welding speed and plunge depth were chosen for conducting the experiments because, which influence and meet the important phenomena of frictional stir welding such as, frictional heat, plastic deformation, stirring, mixing of material, surface appearance, and maintaining the contact. During preliminary experiments tool rotational speed less than $900 \mathrm{rpm}$ the tunnel defects were observed in the weld joints, it may be due to the inadequate heat generation and material transformation. At tool rotational speed above $1100 \mathrm{rpm}$, tunnel defect was observed. It may be due to the too much turbulence caused by higher tool rotational speed. From these observations the range of tool rotational speed was decided from $900 \mathrm{rpm}$ $1100 \mathrm{rpm}$. When the welding speed was increased more than $190 \mathrm{~mm} / \mathrm{min}$ defects were obtained in the joints for entire length of the weld. Same defects were observed when welding speed less than $100 \mathrm{~mm} / \mathrm{min}$ and rough surface appearance. If the plunge depth increased more than $0.3 \mathrm{~mm}$ the edge of the pin touched the backing bar of the fixture during welding because the thickness of the material is 4 $\mathrm{mm}$ and pin length is $3.7 \mathrm{~mm}$, similarly less than $0.1 \mathrm{~mm}$ of plunging depth could not be produced the adequate plastic deformation and frictional heat results in tunnel defect at bottom of the weld. From these observations the range of welding speed was considered from $100 \mathrm{~mm} / \mathrm{min}$ to 190 $\mathrm{mm} / \mathrm{min}$ and plunging depth was considered from $0.1 \mathrm{~mm}$ to $0.3 \mathrm{~mm}$ to conduct the final experiments. The L9 orthogonal array was utilized to plan the experiments (Table 3 ). The tool rotated in the clockwise direction.

Table 1. Chemical composition (wt \%) of AA5086 and AA6061 aluminium alloys used in this investigation.

\begin{tabular}{lccccccc}
\hline Alloys & $\mathrm{Cr}$ & $\mathrm{Cu}$ & $\mathrm{Fe}$ & $\mathrm{Mg}$ & $\mathrm{Mn}$ & $\mathrm{Si}$ & $\mathrm{Al}$ \\
\hline AA5086 & 0.08 & 0.05 & 0.4 & 4.3 & 0.4 & 0.3 & Balance \\
AA6061 & 0.05 & 0.25 & 0.7 & 1.25 & 0.12 & 0.6 & Balance \\
\hline
\end{tabular}

Table 2. Mechanical properties of aluminium alloys used in this investigation.

\begin{tabular}{lcc}
\hline Mechanical Property & AA5086 & AA6061 \\
\hline Ultimate tensile strength (MPa) & 250 & 300 \\
Yield strength (MPa) & 212 & 260 \\
Elongation (\%) & 21 & 19 \\
\hline
\end{tabular}

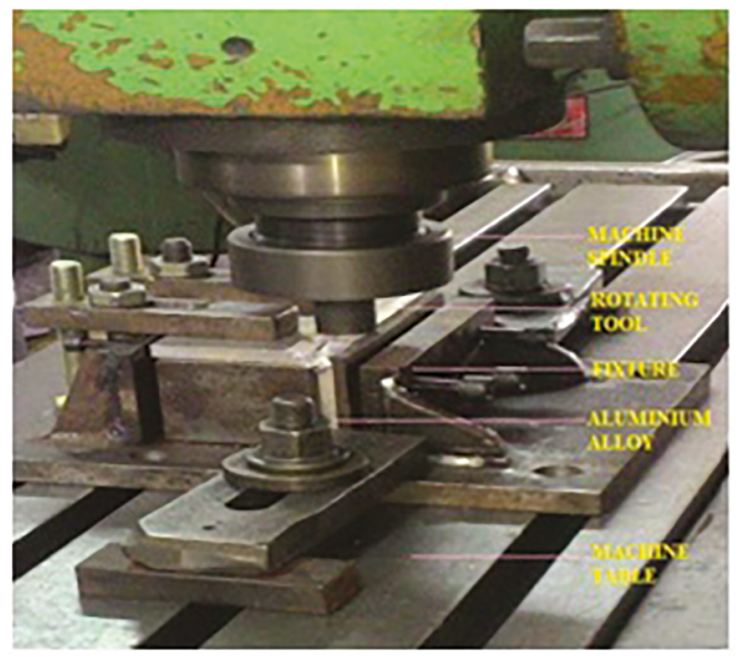

Figure 1. Vertical milling machine with FSW fixture.

Table 3. L9 orthogonal array.

\begin{tabular}{cccc}
\hline Exp. No. & $\begin{array}{c}\text { Rotation speed } \\
(\mathrm{rpm})\end{array}$ & $\begin{array}{c}\text { Welding speed } \\
(\mathrm{mm} / \mathrm{min})\end{array}$ & $\begin{array}{c}\text { Plunge depth } \\
(\mathrm{mm})\end{array}$ \\
\hline A & 900 & 100 & 0.1 \\
B & 900 & 150 & 0.2 \\
C & 900 & 190 & 0.3 \\
D & 1000 & 100 & 0.2 \\
E & 1000 & 150 & 0.3 \\
F & 1000 & 190 & 0.1 \\
G & 1100 & 100 & 0.3 \\
H & 1100 & 150 & 0.1 \\
I & 1100 & 190 & 0.2 \\
\hline
\end{tabular}


The samples were cut from the welded plates normal to FSW line for microstructural characterization. The samples were polished with different grades of emery sheets for metallographic examination. Alumina powder was utilized for final polishing in the disc polishing machine. The samples were etched with standard Keller's reagent according to the standard metallographic procedure. The microstructure of the weld was captured using an optical microscope (OLYMPUS-BX61) and scanning electron microscope (HITACHI-S3400N). The tensile specimens were cut normal to the weld joint and prepared. Three specimens were prepared from each joint and the average value was considered for investigation. The ultimate tensile strength (UTS) was evaluated utilizing a computerized universal testing machine (INSTRON-8801). A specially designed clamp was employed to hold the tensile samples in the UTM. The fractured surfaces of tensile samples, which revealed maximum tensile strength, were analyzed using scanning electron microscope. A Vickers microhardness analyzer (METCO) was utilized for measuring the hardness at the transverse direction of the weld joint with the load of $50 \mathrm{~g}$ and dwell time of $15 \mathrm{~s}$.

The vertical force during friction stir welding was recorded utilizing strain gage (CF350-3AA(II)- TO-F-V2) for various welding and rotational speeds. The $300 \Omega$ impedance strain gage was fixed at $10 \mathrm{~mm}$ away and normal to weld line on the workpiece. The ends of the strain gauge were connected to the amplifier to record the force. The spindle motor electric current consumption during friction stir welding was monitored for different trials, using Mastech M266 Digital AC clamp meter. The jaws of the clamp meter were clamped over the wire of the vertical milling machine during welding. The current was measured at no load and load conditions. The temperature produced during friction stir welding was measured using MASTECH MS6500 K-Type thermocouple digital thermometer with a $0.25 \mathrm{~mm}$ diameter wire. The wire was embedded into a small hole at the depth of $3 \mathrm{~mm}$ away from $10 \mathrm{~mm}$ of weld line.

\section{Results and Discussions}

\subsection{Temperature distribution analysis}

The temperature distribution during friction stir welding was measured with respect to time. The normal temperature distribution was measured by the thermocouple for various rotational speeds of 900,1000 and $1100 \mathrm{rpm}$ at the constant welding speed of $100 \mathrm{~mm} / \mathrm{min}$ appeared in Figure 2. It was seen that the temperature increases with increase in rotational speed of the tool. As the rotation speed increases the contact per unit area of tool and base material interface was enhanced so the increase in temperature to $347^{\circ} \mathrm{C}$ at the rotational speed of $1100 \mathrm{rpm}$ and the welding speed of $100 \mathrm{~mm} / \mathrm{min}$. The lowest value of temperatures $318^{\circ} \mathrm{C}$ and $332^{\circ} \mathrm{C}$ produced at the rotational speeds of $900 \mathrm{rpm}$ and $1000 \mathrm{rpm}$. The higher temperature was noticed at the center line of the weld. Temperature distribution during welding was due to frictional heat produced by rubbing action of the tool. The quality of weld depends upon heat dissipated rate during the process ${ }^{19-21}$.

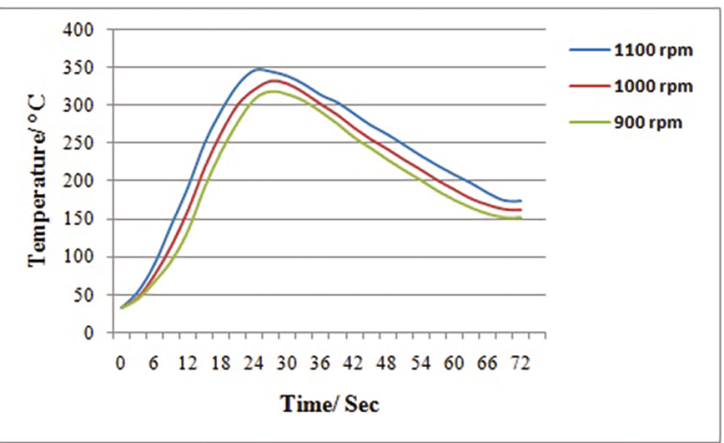

Figure 2. Temperature distribution during FSW at rotation speeds of 900, 1000, $1100 \mathrm{rpm}$ and constant welding speed of $100 \mathrm{~mm} / \mathrm{min}$.

\subsection{Force generation analysis}

During friction stir welding, three forces acting on the workpiece namely, transverse force, longitudinal force and downward force in the $\mathrm{X}, \mathrm{Y}$ and $\mathrm{Z}$ directions respectively. Figure 3 demonstrates the welding force produced at the rotational speeds of 900,1000 and $1100 \mathrm{rpm}$ and the constant welding speed of $100 \mathrm{rpm}$. The variation of the process parameters has a specific impact on the force generated during the FSW process. The downward force reached peak value during the plunging of the tool between materials to be joined and when the shoulder touches the surface of the material. Two peak values were recorded for the downward force at the rotational speed of $900 \mathrm{rpm}$, the first peak value of $4.3 \mathrm{kN}$ reveals the force acting on the pin during plunging into the base material and the second peak value of $4.5 \mathrm{kN}$ represents the force acting on the shoulder contact with the base material. Then force reduced significantly and remained steady state value of $3.7 \mathrm{kN}$ during the translational stage till the tool leaves the material.

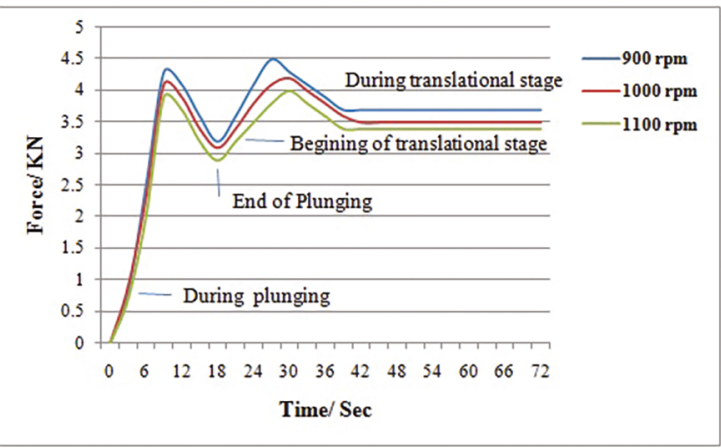

Figure 3. Vertical force generation during FSW at rotation speeds of $900,1000,1100 \mathrm{rpm}$ and constant welding speed of $100 \mathrm{~mm} / \mathrm{min}$. 
The tool shoulder was the principle driving element of downward force. The downward force was increased with increase in welding speed. This may because of a reduction in thermal softening of the material. The downward force decreases with increasing the rotational speed of the tool. This may because of the temperature of the material increased with increase in rotational speed, so the material thermally softened and a plasticized more rapidly ${ }^{4,22-24}$.

\subsection{Spindle motor current analysis}

The current flow through the main spindle motor at various stages of the friction stir welding was measured. Figure 4 reveals current flow through the motor at rotation speeds of 900,1000 and $1100 \mathrm{rpm}$ and the constant welding speed of $100 \mathrm{~mm} / \mathrm{min}$. The first peak value of current was recorded when the auxiliary motors such as the hydraulic pump, electrical motors, and auxiliary devices were turned on. The current flow through the auxiliary motors during no-load condition was obtained 1.6 A. During the plunging stage, current flow increases rapidly and reaching the peak value of 3.1 A when the tool shoulder touches the top surface of the material. Then current gradually decreases to $2.2 \mathrm{~A}$ because of the material soften due to frictional heat produced by the stirring action of the tool. At the end of plunging stage, the motor current was rapidly increased to $4.8 \mathrm{~A}$ when the tool tends to move because the colder material was experienced by the tool and remained steady state till the end of the process. It was found that the current flow was increased to $4.9 \mathrm{~A}$ at the rotation speed of $900 \mathrm{rpm}$ and decreased to $4.5 \mathrm{~A}$ at the rotation speed of $1100 \mathrm{rpm}$. After finishing of the welding, the tool was lifted out of the plates, and current decreased quickly to the value of no-load condition ${ }^{25,26}$.

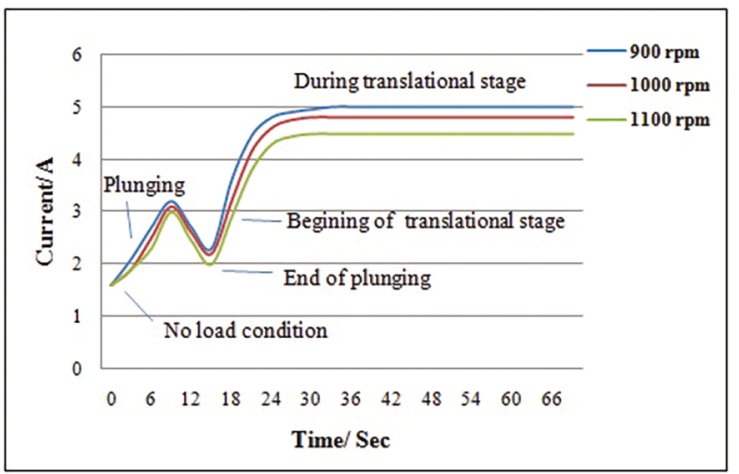

Figure 4. Electric current consumption during FSW at rotation speeds of $900,1000,1100 \mathrm{rpm}$ and constant welding speed of $100 \mathrm{~mm} / \mathrm{min}$.

\subsection{Microstructure}

Figures 5-7 show the optical micrographs of the crosssection normal to the tool traverse direction of the weld. Three distinct zones such as stir zone, thermomechanically affected zone, and heat affected zone have been recognized. Figures 5(a), 6(a) and 7(a) demonstrate the microstructure of parent material. Figures 5(b), 6(b) and 7(b) demonstrate the microstructure of heat affected zones. It was hard to find the difference in grain structure of parent material and heat affected zone because of low thermal affectability. Figures 5(c), 6(c) and 7(c) show the microstructure of the thermomechanically affected zones (TMAZ). The boundary between the weld zone and the thermomechanically affected zone was seen clearly. Heat affected zone and thermomechanically affected zone developed the transition zone. Thermomechanically affected zone indicates highly extended grains of the aluminium alloy without recrystallization. Both sides of the thermomechanically affected zone revealed a similar microstructure. It was seen that the microstructure of the stir zone separated from the deformed zone of the TMAZ. The thermomechanically affected zone was thermally affected and deformed plastically not recrystallized.

Figure 7(c) shows the lamellar flow of dissimilar materials in the stir zone. Figures 5(d), 6(d) and 7(d) reveal the microstructure of the stir zone. The stir zone experienced the high temperature and the heavy plastic deformation. The heavy plastic deformation produces fine-equiaxed recrystallized grains in stir zone followed by dynamic recrystallization. The frictional heat produced during welding was the reason for grain refinement in the weld zone, which could increase the strength of the weld. The defects of fusion welding such as porosity, slag inclusion, and voids were not found in the weld zone $\mathrm{e}^{5,8,11}$.

\subsection{SEM analysis}

Figures 8(a), (b) and (c) demonstrate the SEM micrographs of the stir zones welded at the parameters of the rotational speed at $1000 \mathrm{rpm}$ and the welding speed at $150 \mathrm{~mm} / \mathrm{min}$. Figure 8(a) reveals microstructure of the stir zone at the AA5086 side, which indicates broken precipitates found in the stirred zone, may be produced by the rigorous deformation of the material during FSW process. Figure 8(b) shows microstructure of the stir zone at AA 6061 side, which consists fine equiaxed grains because of the plastic deformation and frictional heat produced by the rotating tool. The typical grain size in the weld zone was around 9 to $10 \mu \mathrm{m}$, which substantially smaller than the base material. The particle size of the weld zone decreased with increasing of welding speed ${ }^{7,8}$. 


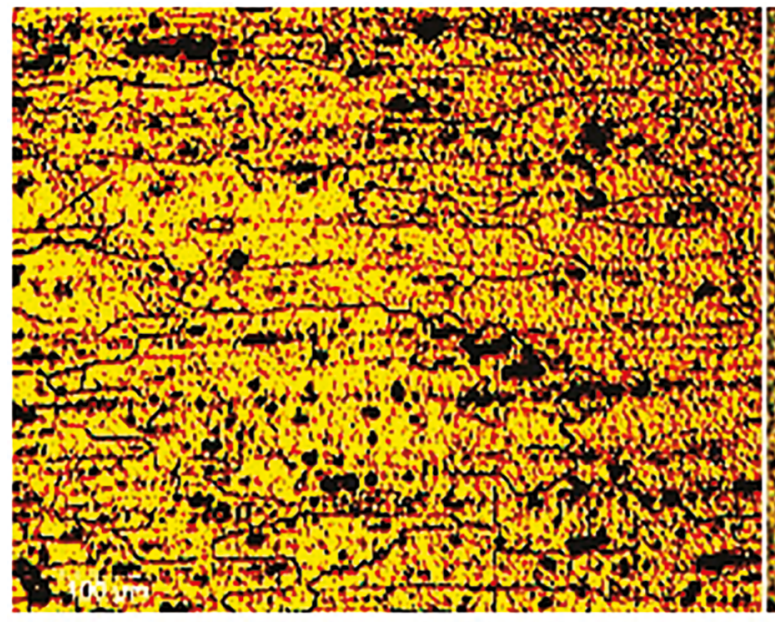

(a) Base metal AA6061

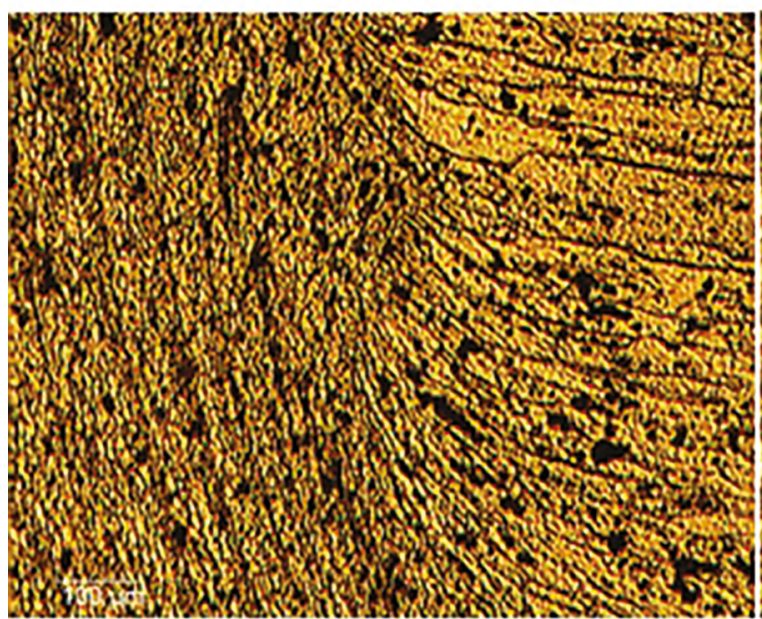

(c) Thermo mechanically affected zone

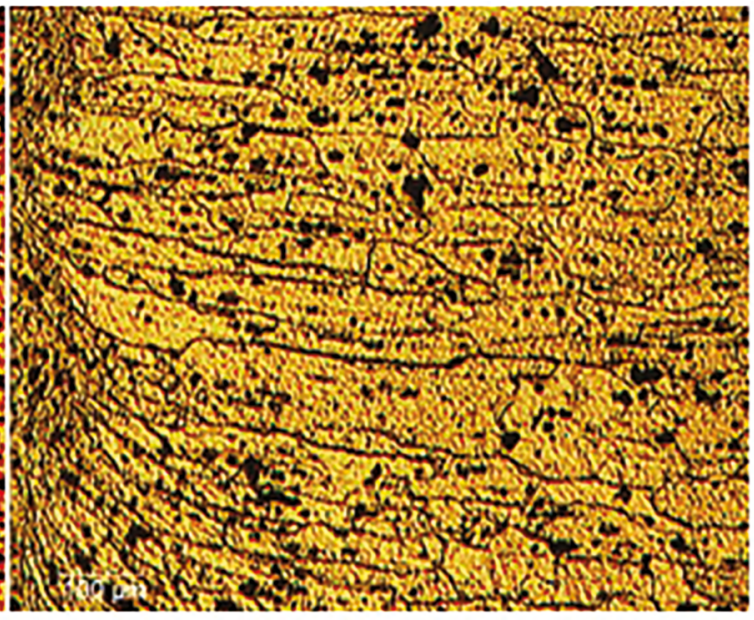

(b) Heat affected zone

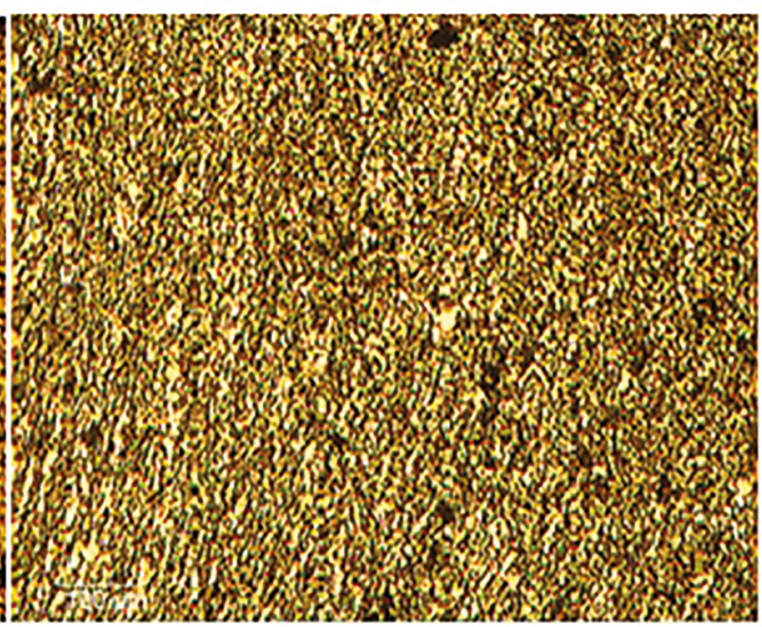

(d) Stir Zone

Figure 5. Optical micrographs at welding and rotational speeds of $100 \mathrm{~mm} / \mathrm{min}$ and $1100 \mathrm{rpm}$.

\subsection{Tensile property}

The results demonstrate that the tensile properties of the welded joints remarkably fluctuated with respect to various welding and rotational speeds. A higher tensile strength of $192 \mathrm{MPa}$ was achieved in the weld fabricated by $1000 \mathrm{rpm}$ of rotational speed and $150 \mathrm{~mm} / \mathrm{min}$ of welding speed, which was $76.80 \%$ of the aluminium alloy base material. A lower tensile strength of $148 \mathrm{MPa}$ was and obtained in the weld made by $900 \mathrm{rpm}$ of rotational speed, $100 \mathrm{~mm} / \mathrm{min}$ of welding speed which was $59.20 \%$ of the base material. A noteworthy increase in welding speed improved weld quality and joint mechanical properties. The impact of welding speed on the tensile strength of the joints is shown in Figure 9. The lower tensile strength was obtained at the lower and the higher welding speeds of 100 and 190 $\mathrm{mm} / \mathrm{min}$. The joints fabricated with lower welding speed produced high temperature but low cooling rate followed by coarsening of grains so the reduction of ultimate tensile strength because of defects, higher welding speed caused insufficient stirring thus lower heat generation with quicker cooling rate subsequently lower ultimate tensile strength. The plasticization of material, particle size, and defects were affected by welding speed. All the samples were broken at heat affected zone during the tensile test. But failure occurred at the weld zone fabricated at the welding speed of $100 \mathrm{~mm} /$ min and the rotational speed of $900 \mathrm{rpm}^{9,11,14}$. 


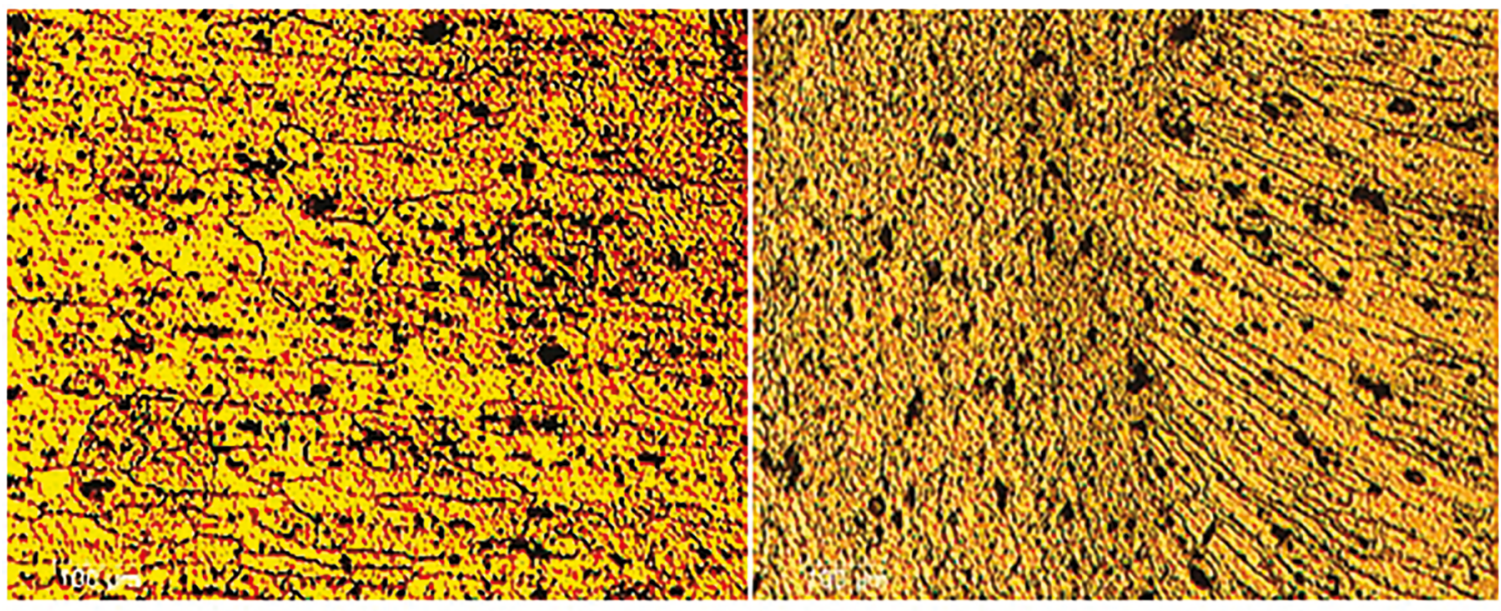

(a) Base metal AA6061

(b) Heat affected zone

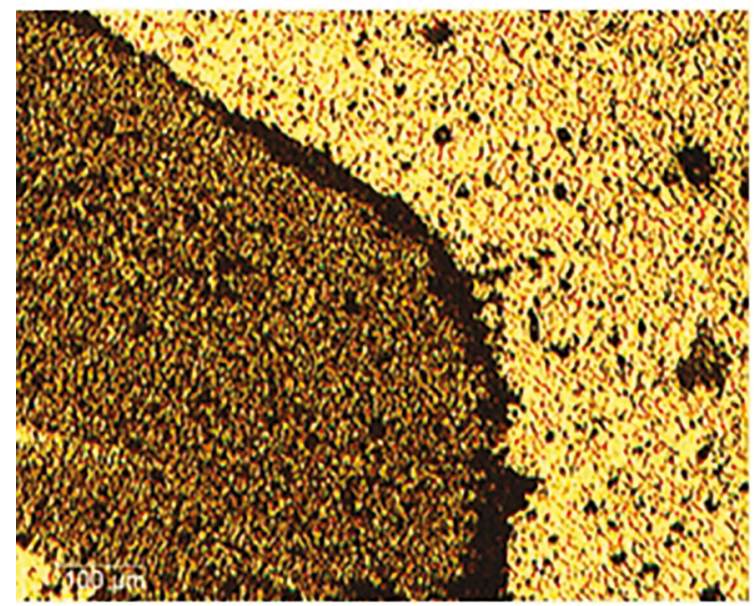

(c) Themomechanially affected zone

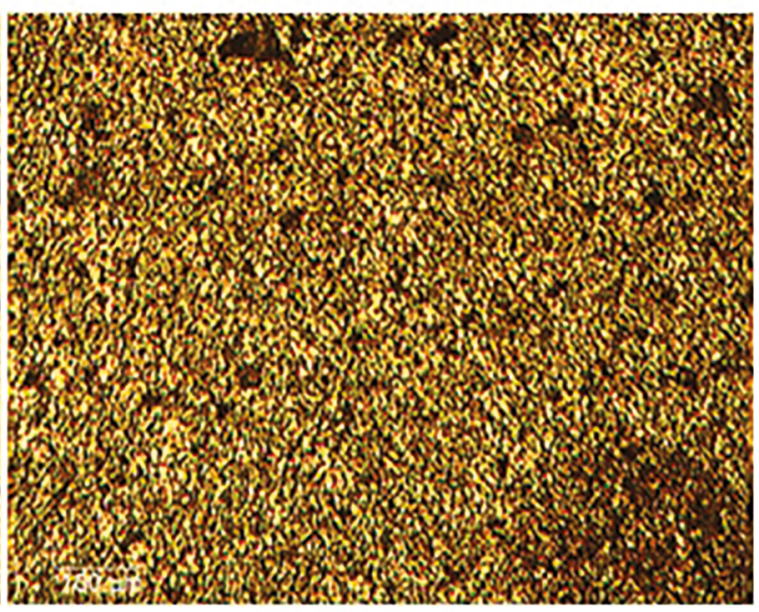

(d) Stir zone.

Figure 6. Optical micrographs at welding and rotational speeds of $150 \mathrm{~mm} / \mathrm{min}$ and $1100 \mathrm{rpm}$.

\subsection{Hardness distribution}

Figures 10-12 illustrate the microhardness profiles of the FSW AA5086 and AA6061 dissimilar aluminium alloys at various welding speeds of 100,150 , and $190 \mathrm{~mm} / \mathrm{min}$ and rotational speeds of 900,1000 , and $1100 \mathrm{rpm}$. It was observed that higher rotation speeds produced the increase in hardness values of the welds. The microhardness profile was reached the maximum value of $157 \mathrm{HV}$ in the thermomechanically affected zone at the rotational and welding speeds of 1100 $\mathrm{rpm}$ and $150 \mathrm{~mm} / \mathrm{min}$. The minimum microhardness value of $76 \mathrm{HV}$ was observed at the welding speed of $150 \mathrm{~mm} / \mathrm{min}$ and the rotational speed of $900 \mathrm{rpm}$. The average hardness value $101 \mathrm{HV}$ was obtained.

The mechanical properties extremely affected by the thermal conditions of the welding. The high temperature was generated and material was softened at the low welding speed of $100 \mathrm{~mm} / \mathrm{min}$, the long time needed for dissipation of heat from the weld zone results in lower hardness value. The maximum and minimum hardness values of $157 \mathrm{HV}$ and 90 $\mathrm{HV}$ were obtained in the thermomechanically affected zone at the welding speed of $150 \mathrm{~mm} / \mathrm{min}$ and the rotational speed of $1100 \mathrm{rpm}$. It was found that the maximum value of the hardnesses $97 \mathrm{HV}$ and $110 \mathrm{HV}$ were observed at the welding speeds of $1000 \mathrm{rpm}$ and $900 \mathrm{rpm}$. Moreover, it was found that the hardness value of the retreating side was comparatively higher than that of the alternative side. The higher value of microhardness was obtained in the stir zone than that of the heat affected zone and thermomechanically affected zone regions. The lower hardness values were recorded at heat affected zone than the parent material. The welding speed greatly affects the microstructure of the weld results in the influence of microhardness distribution ${ }^{16,27,28}$. 


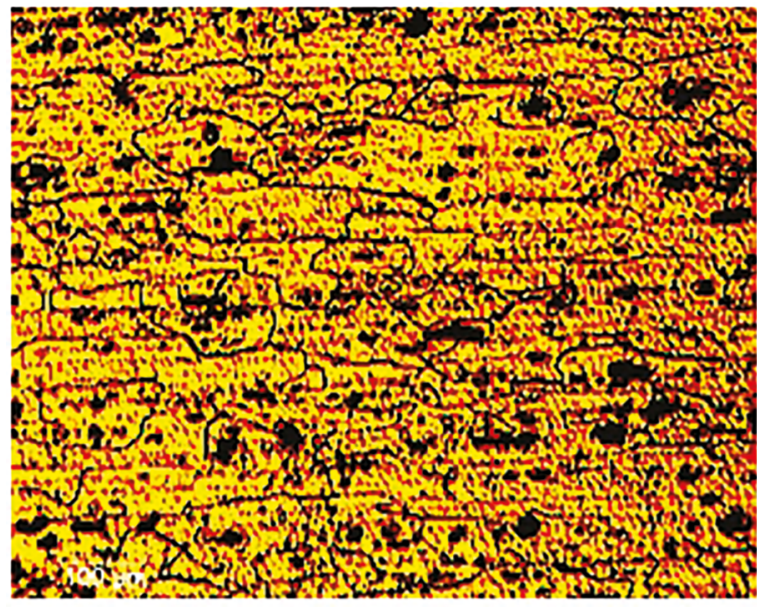

(a) Base metal AA6061

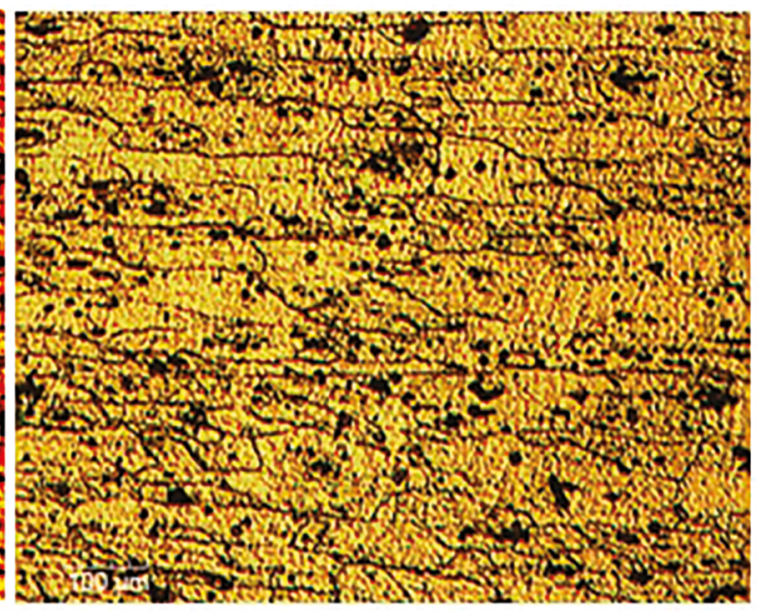

(b) Heat affected zone

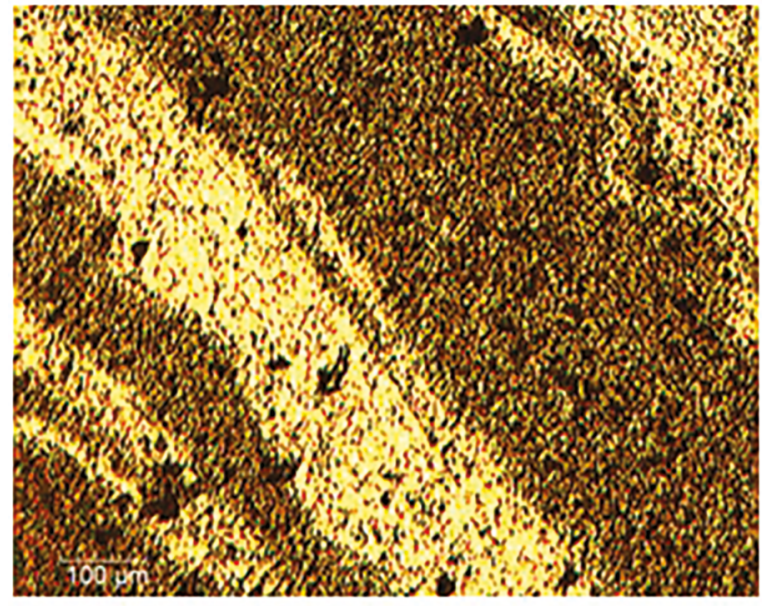

(c) Themomechanially affected zone

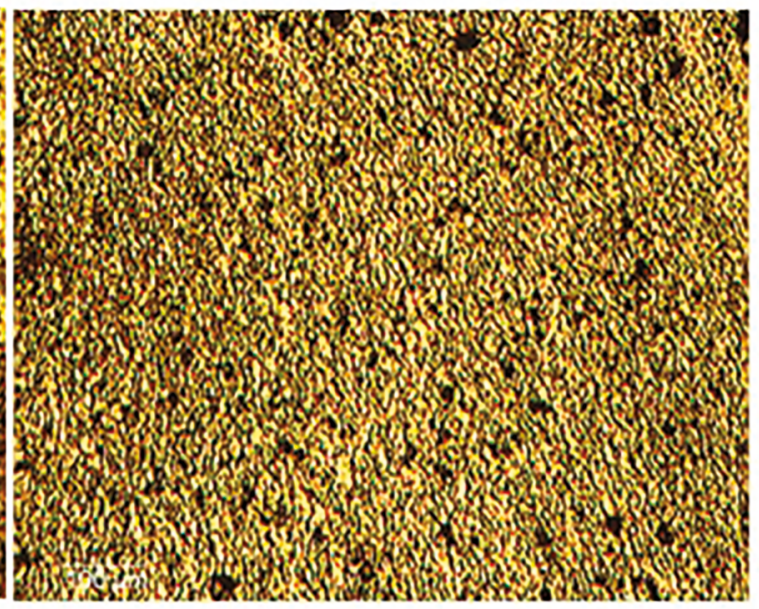

(d) Stir zone

Figure 7. Optical micrographs at welding and rotational speeds of $190 \mathrm{~mm} / \mathrm{min}$ and $1100 \mathrm{rpm}$.

\subsection{Fractography}

Figure 13 illustrates SEM images of the fractured surfaces of the tensile tested specimen, fabricated at the welding speed of $150 \mathrm{~mm} / \mathrm{min}$ and the rotational speed of $1000 \mathrm{rpm}$. Figure 13(a) demonstrates the large-scale view of the fractured surface that indicates a homogeneously rough surface. The ductile fractured feature with voids nucleation and coalescence was observed in the enlarged view of the fractured surface. A large number of dimples with different depth signify that the ductile fracture occurred in these regions. These dimples were the responsible for fractured at the heat-affected zone ${ }^{18,19}$.

\subsection{Optimization of process parameters}

The ultimate tensile strength, microhardness at various regions of the weld zone, temperature distribution, vertical force generation and current consumption were the output responses considered for strength of the weld. The Taguchi grey relational analysis was used to optimize the process parameters because few of the responses have to be maximum such as tensile strength and temperature distribution. The other responses have to be minimum such as, microhardness, force generation and current consumption. In the grey relational analysis, the multi-response problem is converted in to single response problem. The output data were normalized between the ranges of 0 to 1 to determine grey relational grade (table 4). The interaction plot (Figure 14) was drawn using grey relational grade and it was observed that the optimum process parameters are rotational speed of 1000 $\mathrm{rpm}$, welding speed of $150 \mathrm{~mm} / \mathrm{min}$ and plunge depth of $0.3 \mathrm{~mm}$ exhibit maximum weld strength than that of other parameters $^{29}$. 


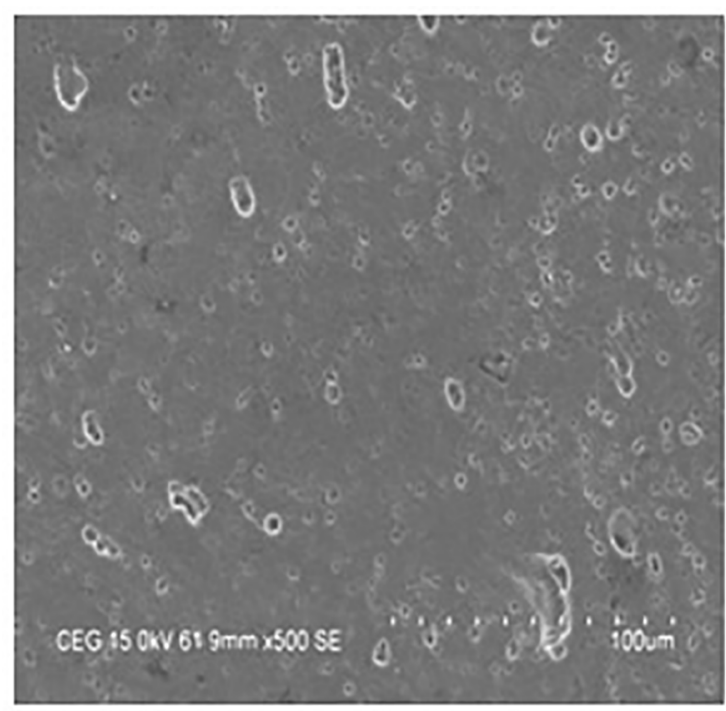

(a) Stir zone at AA5086 side

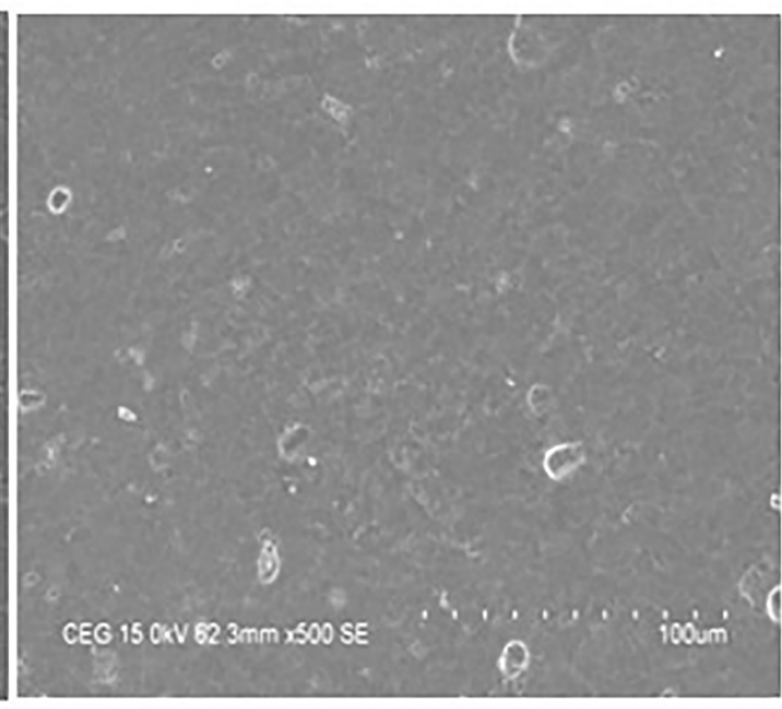

(b) Stir zone at AA6061 side

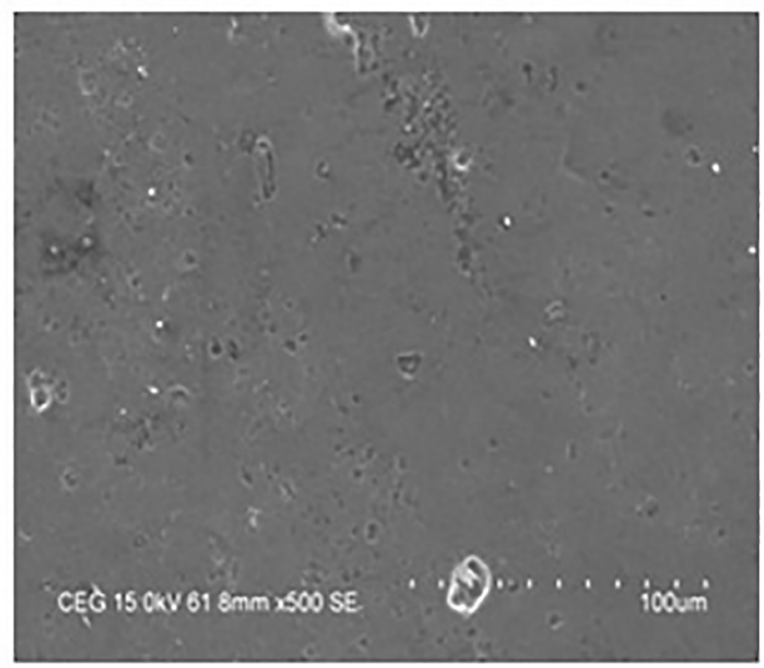

(c) Stir zone

Figure 8. SEM micrographs.

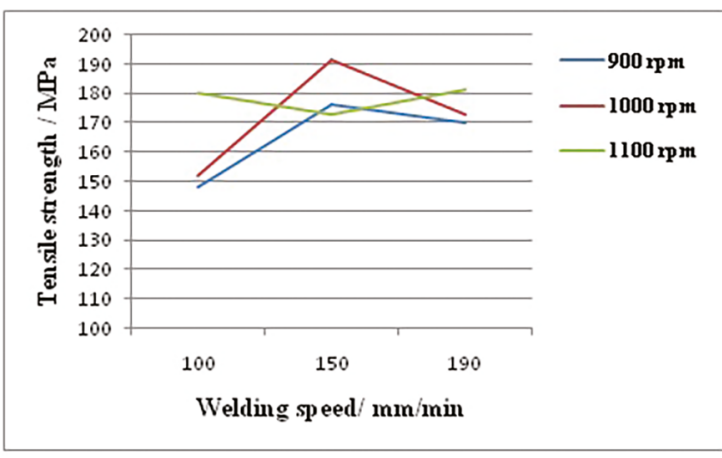

Figure 9. Effect of welding speed on ultimate tensile strength.

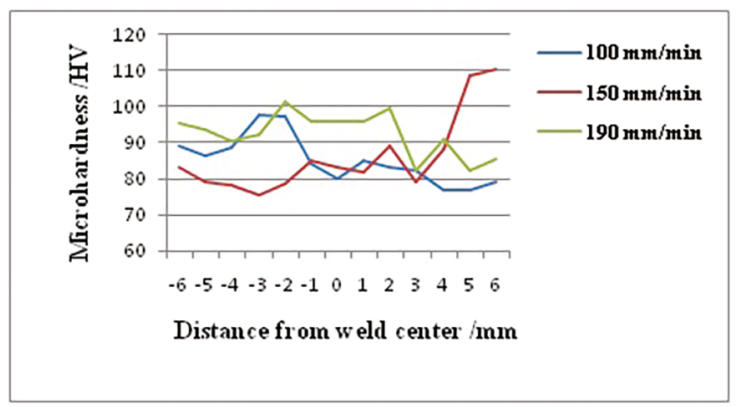

Figure 10. Microhardness of joints obtained at welding speeds of 100,150 and $190 \mathrm{~mm} / \mathrm{min}$ at rotational speed of $900 \mathrm{rpm}$. 


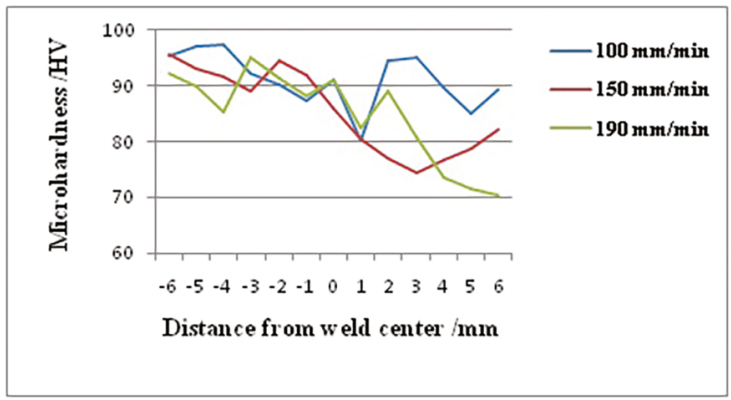

Figure 11. Microhardness of joints obtained at welding speeds of 100,150 and $190 \mathrm{~mm} / \mathrm{min}$ at rotational speed of $1000 \mathrm{rpm}$.
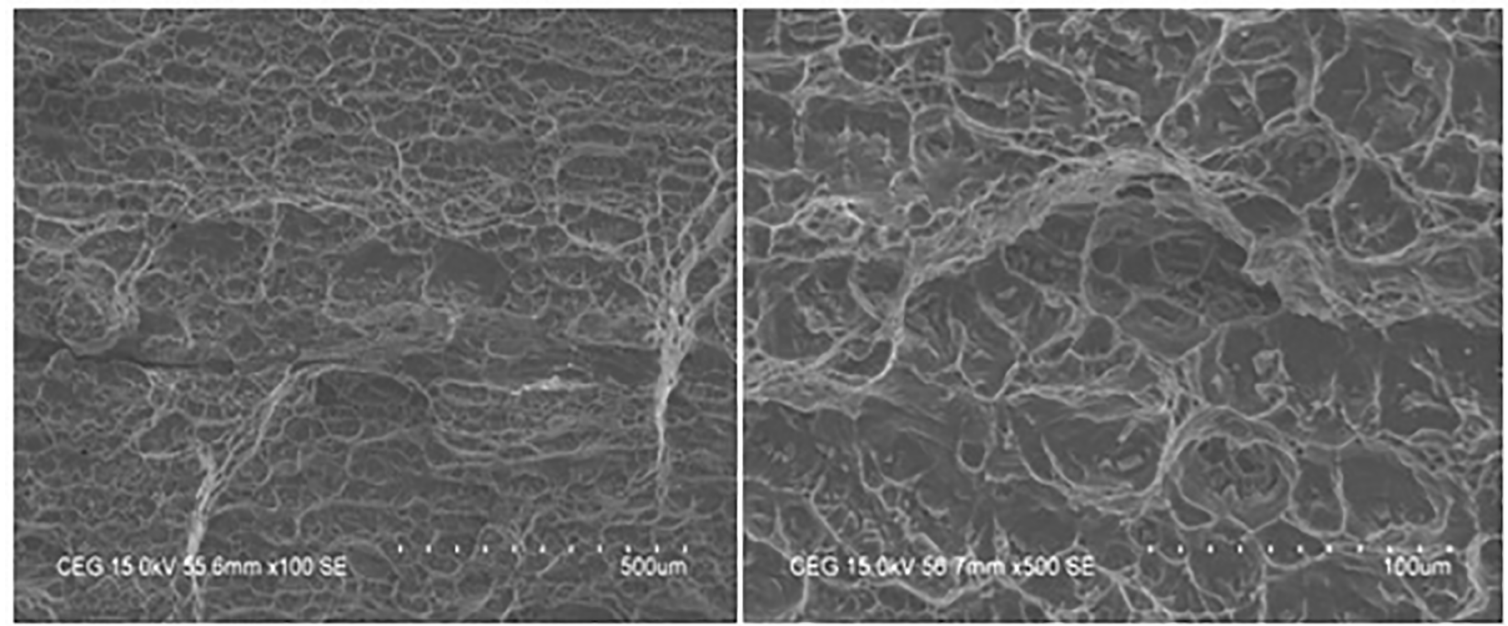

Figure 13. Fractographs of friction stir welded tensile test specimen at the welding and rotational speed of $150 \mathrm{~mm} / \mathrm{min}$ and $1000 \mathrm{rpm}$.

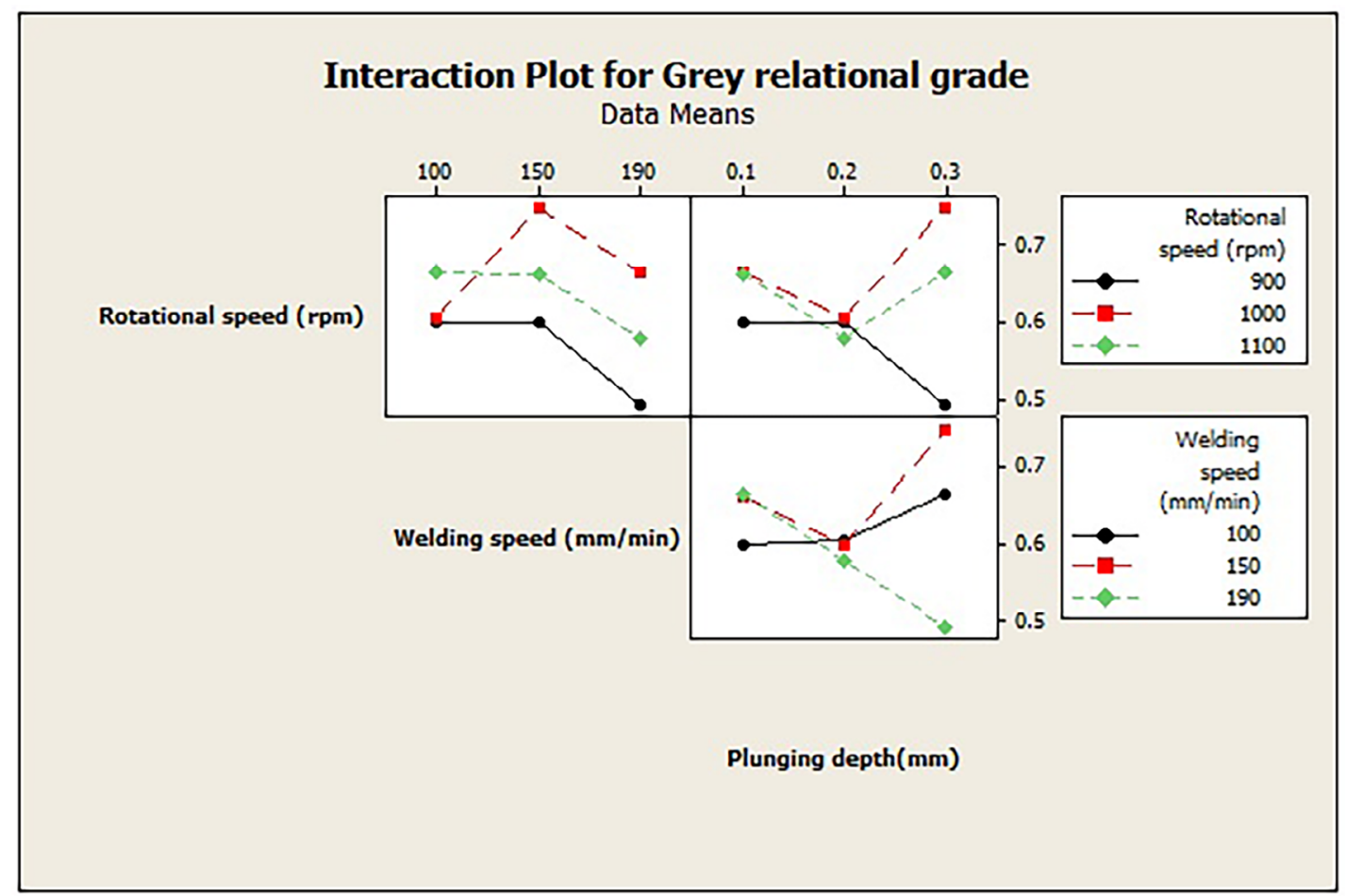

Figure 14. Interaction plot for grey relational grade. 
Table 4. Grey relational grades.

\begin{tabular}{ccccc}
\hline $\begin{array}{c}\text { Exp. } \\
\text { No. }\end{array}$ & $\begin{array}{c}\text { Rotation } \\
\text { speed } \\
(\mathrm{rpm})\end{array}$ & $\begin{array}{c}\text { Welding } \\
\text { speed } \\
(\mathrm{mm} / \mathrm{min})\end{array}$ & $\begin{array}{c}\text { Plunge } \\
\text { depth } \\
(\mathrm{mm})\end{array}$ & $\begin{array}{c}\text { Grey } \\
\text { relational } \\
\text { grade }\end{array}$ \\
\hline A & 900 & 100 & 0.1 & 0.592 \\
B & 900 & 150 & 0.2 & 0.655 \\
C & 900 & 190 & 0.3 & 0.528 \\
D & 1000 & 100 & 0.2 & 0.564 \\
E & 1000 & 150 & 0.3 & 0.767 \\
F & 1000 & 190 & 0.1 & 0.685 \\
G & 1100 & 100 & 0.3 & 0.628 \\
H & 1100 & 150 & 0.1 & 0.702 \\
I & 1100 & 190 & 0.2 & 0.573 \\
\hline
\end{tabular}

\section{Conclusion}

In the present investigation, mechanical and metallurgical properties of friction stir welded dissimilar thickness corner joints of AA5086 and AA6061 dissimilar alloys were studied. From the microstructural, hardness and tensile investigations the following conclusions were drawn:

1. The FSW joint produced at a welding speed of 150 $\mathrm{mm} / \mathrm{min}$ and rotational speed of $1000 \mathrm{rpm}$ was defect-free and revealed better mechanical and metallurgical properties. Furthermore, the surface morphology of the weld zone was observed uniform with an increase of tool rotation speed.

2. The maximum FSW joint tensile strength of 192 MPa was obtained, which is $76.80 \%$ of the parent material and minimum tensile strength of $148 \mathrm{MPa}$ was obtained, which is $59.20 \%$ of the base material.

3. Hardness at stir zone was observed to be maximum, which was higher than that of the base material because of significant grain refinement. The maximum hardness $157 \mathrm{HV}$ was obtained at thermomechanically affected zone.

4. The fracture positions of all joints located at heat affected zone that reveals defect-free weld zone.

5. The peak temperature of $347^{\circ} \mathrm{C}$ was obtained at rotational speed of $1100 \mathrm{rpm}$, welding speed of $100 \mathrm{~mm} / \mathrm{min}$ and tool plunge depth of $0.1 \mathrm{~mm}$.

6. The downward force reaches the peak value of $4.3 \mathrm{kN}$ during plunging of the tool shoulder on the surface of the material. Then force reduced significantly to $3.2 \mathrm{kN}$ and again increased to 4.5 $\mathrm{kN}$ then decreased to $3.7 \mathrm{kN}$ and remained steady state during the translational stage till the tool leaves the material.
7. Electric current consumption during welding was 1.6 $\mathrm{A}$ at no load condition and rapidly increased to $2.8 \mathrm{~A}$ during plunging of the tool and again gradually decreased to 2.1 A then increased to 5.2 A and remained steady state during the translational stage of the tool till the end.

The methodology and results of this FSW experimental work on dissimilar thickness corner joint will be reassuring to produce FSW corner joints with optimum strength for joining non-heat treatable AA5086 and heat treatable AA6061 aluminium alloys, besides engaging an appropriate condition monitoring systems.

\section{References}

1. Martin JP, Stanhope C, Gascoyne S. Novel techniques for corner joints using friction stir welding. In: TMS 2001 Annual Meeting \& Exhibition; 2011 Feb 27-Mar 3; San Diego, CA, USA. Friction Stir Welding and Processing VI. p. 177-186.

2. Ilangovan M, Rajendra Boopathy S, Balasubramanian V. Effect of tool pin profile on microstructure and tensile properties of friction stir welded dissimilar AA 6061-AA 5086 aluminium alloy joints. Defence Technology. 2015;11(2):174-184.

3. Yan Y, Zhang D, Cheng Q, Zhang W. Dissimilar friction stir welding between 5052 aluminum alloy and AZ31 magnesium alloy. Transactions of Nonferrous Metals Society of China. 2010;20(Suppl 2):s619-s623.

4. Ahmed MMZ, Ataya S, El-Sayed Seleman MM, Ammar HR, Ahmed E. Friction stir welding of similar and dissimilar AA7075 and AA5083. Journal of Materials Processing Technology. 2017;242:77-91

5. Palanivel R, Koshy Mathews P, Dinaharan I, Murugan N. Mechanical and metallurgical properties of dissimilar friction stir welded AA5083-H111 and AA6351-T6 aluminum alloys. Transactions of Nonferrous Metals Society of China. 2012;24(1):58-65.

6. Ahn BW, Choi DH, Kim YH, Jung SB. Fabrication of $\mathrm{SiC}_{\mathrm{p}} / \mathrm{AA} 5083$ composite via friction stir welding. Transactions of Nonferrous Metals Society of China. 2012;22(Suppl 3):s634-s638.

7. Akinlabi ET, Andrews A, Akinlabi SA. Effects of processing parameters on corrosion properties of dissimilar friction stir welds of aluminium and copper. Transactions of Nonferrous Metals Society of China. 2014;24(5):1323-1330.

8. Dinaharan I, Murugan N. Effect of friction stir welding on microstructure, mechanical and wear properties of AA6061/ $\mathrm{ZrB}_{2}$ in-situ cast composites. Materials Science and Engineering: A. 2012;543:257-266.

9. Kalaiselvan K, Murugan N. Role of friction stir welding parameters on the tensile strength of AA6061-B4C composite joints. Transactions of Nonferrous Metals Society of China. 2013;23(3):616-624. 
10. Fahimpour V, Sadrnezhaad SK, Karimzadeh F. Corrosion behavior of aluminum 6061 alloys joined by friction stir welding and gas tungsten arc welding methods. Materials \& Design. 2012;39:329-333.

11. Lakshminarayanan AK, Saranarayanan R, Karthik Srinivas V, Venkatraman B. Characteristics of friction welded AZ31B magnesium-commercial pure titanium dissimilar joints. Journal of Magnesium and Alloys. 2015;3(4):315-321.

12. Dorbane A, Mansoor B, Ayoub G, Shunmugasamy VC, Imad A. Mechanical, microstructural and fracture properties of dissimilar welds produced by friction stir welding of AZ31B and A16061. Materials Science \& Engineering: A. 2016;651:720-733.

13. Guo JF, Chen HC, Sun CN, Bi G, Sun Z, Wei J. Friction stir welding of dissimilar materials between AA6061 and AA7075 $\mathrm{Al}$ alloys effects of process parameters. Materials \& Design (1980-2015). 2014;56:185-192.

14. Dawood HI, Mohammed KS, Rahmat A, Udai MB. Effect of small tool pin profiles on microstructures and mechanical properties of 6061 aluminum alloy by friction stir welding. Transactions of Nonferrous Metals Society of China. 2015;25(9):2856-2865.

15. Srinivasa Rao T, Madhusudhan Reddy G, Koteswara Rao SR. Microstructure and mechanical properties of friction stir welded AA7075-T651 aluminum alloy thick plates. Transactions of Nonferrous Metals Society of China. 2015;25(6):1770-1778.

16. Khan NZ, Siddiquee AN, Khan ZA, Mukhopadhyay AK. The mechanical and microstructural behavior of friction stir welded similar and dissimilar sheets of AA2219 and AA7475 aluminium alloys. Journal of Alloys and Compounds. 2017;695:2902-2908.

17. Palanivel R, Koshy Mathews P. Prediction and optimization of process parameter of friction stir welded AA5083-H111 aluminum alloy using response surface methodology. Journal of Central South University. 2012;19(1):1-8.

18. Li X, Zhang D, Qiu C, Zhang W. Microstructure and mechanical properties of dissimilar pure copper/1350 aluminum alloy butt joints by friction stir welding. Transactions of Nonferrous Metals Society of China. 2012;22(6):1298-1306.

19. Tan CW, Jiang ZG, Li LQ, Chen YB, Chen XY. Microstructural evolution and mechanical properties of dissimilar $\mathrm{Al}-\mathrm{Cu}$ joints produced by friction stir welding. Materials \& Design . 2013;51:466-473.
20. Aval HJ. Influences of pin profile on the mechanical and microstructural behaviors in dissimilar friction stir welded AA6082-AA7075 butt Joint. Materials and Design. 2015;67:413421.

21. Chao YJ, Qi X, Tang W. Heat Transfer in Friction Stir WeldingExperimental and Numerical Studies. Journal of Manufacturing Science and Engineering. 2003;125(1):138-145.

22. Trimble D, O'Donnell GE, Monaghan J. Characterisation of tool shape and rotational speed for increased speed during friction stir welding of AA2024-T3. Journal of Manufacturing Processes. 2015; 17:141-150.

23. Vukčević M, Plančak M, Janjić M, Šibalić N. Research and analysis of friction stir welding parameters on aluminium alloys (6082-T6). Journal for Technology of Plasticity. 2009;34(12):49-57.

24. Trimble D, Monaghan J, O'Donnel GE. Force generation during friction stir welding of AA2024-T3. CIRP Annals. 2012;61(1):912.

25. Buffa G, Campanella D, Di Lorenzo R, Fratini L, Ingarao G. Analysis of Electrical Energy Demands in Friction Stir Welding of Aluminum Alloys. Procedia Engineering. 2017;183:206-212.

26. Kumar SS, Denis Ashok S, Narayanan S. Investigation of Friction Stir Butt Welded Aluminium Alloy Flat Plates using Spindle Motor Current Monitoring Method. Procedia Engineering. 2013;64:915-925.

27. Liu H, Hu Y, Dou C, Sekulic DP. An effect of the rotation speed on microstructure and mechanical properties of the friction stir welded 2060-T8 Al-Li alloy. Materials Characterization. 2017;123:9-19.

28. Rodriguez RI, Jordon JB, Allison PG, Rushing T, Garcia L. Microstructure and mechanical properties of dissimilar friction stir welding of 6061-to-7050 aluminum alloys. Materials \& Design. 2015;83:60-65.

29. Sahu PK, Pal S. Multi-response optimization of process parameters in friction stir welded AM20 magnesium alloy by Taguchi grey relational analysis. Journal of Magnesium and Alloys. 2015;3(1):36-46. 